\title{
Differences Between Quality of Life in Children with Infrequent and Frequent Relapse of Nephrotic Syndrome
}

\author{
Ni Putu Eka Suwitri ${ }^{*}$ I Ketut Suarta, I Gusti Ayu Trisna Windiani \\ Department of Child Health, Faculty of Medicine, Udayana University, Denpasar, Indonesia \\ Email address: \\ Ekasuwitri86@yahoo.com (Ni P. E. Suwitri), dr.ketut.suarta.spa@gmail.com (I K. Suarta), \\ trisnawindianidr $a$ yahoo.co.id (I G. A. T. Windiani) \\ ${ }^{*}$ Corresponding author
}

\section{To cite this article:}

Ni Putu Eka Suwitri, I Ketut Suarta, I Gusti Ayu Trisna Windiani. Differences Between Quality of Life in Children with Infrequent and Frequent Relapse of Nephrotic Syndrome. American Journal of Pediatrics. Vol. 5, No. 4, 2019, pp. 281-285.

doi: 10.11648/j.ajp.20190504.30

Received: November 15, 2019; Accepted: December 9, 2019; Published: December 19, 2019

\begin{abstract}
Nephrotic syndrome is a common disease in children. The syndrome consists of massive proteinuria, hypoalbuminemia, edema and hypercholesterolemia which may lead to relapse and remission episodes, thus affect child's quality of life. The objective was to determine the quality of life difference between children with infrequent and frequent relapse of nephrotic syndrome. This study was an observational analytic study with cross-sectional design, conducted at the Pediatric outpatient clinic in Sanglah Hospital, Denpasar, Indonesia, from January 2016 to January 2017. Independent t-test was performed to assess quality of life differences in patients with infrequent and frequent relapse of nephrotic syndrome, with significancy level $\mathrm{p}<0.05$ and precision set at $95 \%$ confidence interval. The quality of life in children was measured by PedsQL 4.0 Generic Core Scales Questionnaire. Subjects consisted of 14 infrequent relapse samples and 14 frequent relapse samples. The average scores of quality of life in children based on their parents' reports were 85.70 (8.96) from infrequent relapse group and 82.24 (12.56) from the frequent relapse group ( $\mathrm{p}=0.410)$. Meanwhile, based on the children's report, the quality of life score were 88.79 (9.30) from infrequent relapse group and 82.59 (12.09) from frequent relapse group ( $\mathrm{p}=0.194$ ). This study concluded that there was no significant difference of physical, emotional, social, school functions subscale scores and quality of life score based on children and parents' reports in both groups.
\end{abstract}

Keywords: Nephrotic Syndrome, Relapse, Quality of Life, PedsQL, Children

\section{Introduction}

Nephrotic syndrome is a common disease in children. Nephrotic syndrome is a clinical syndrome characterized by massive proteinuria, hypoalbuminemia, edema and hypercholesterolemia. The natural history of nephrotic syndrome affect children's quality of life [1].

The annual incidence of nephrotic syndrome is $2-4$ cases in every 100,000 children under 16 years old. Nephrotic syndrome can be found in $90 \%$ of pediatric nephrology cases. The incidence of nephrotic syndrome in Indonesia is estimated 6 cases in every 100,000 children aged under 16 years old. The male to female ratio in children is approximately 2:1 [1]. The incidence of nephrotic syndrome in Pediatrics Department of Sanglah Hospital, Denpasar,
Indonesia was about 68 children from 2001 to 2007. Patients' age ranged from 6 months to 11 years old, and the male to female ratio was 2.7:1. Almost all patients came to hospital with chief complaint swelling with massive proteinuria. About $85.2 \%$ of patients were steroid-sensitive and the rest was steroid-resistant [2].

Nephrotic syndrome is a chronic disease characterized by relapse and remission episodes. The natural history of nephrotic syndrome consist of: 76-93\% whom develop relapse, $30 \%$ of them will develop frequent relapse while 10 $20 \%$ will develop infrequent relapse. Meanwhile, the rest will be steroid-dependent [1]. History of severe nephrotic syndrome cases may lead to multiple complications, longterm use of corticosteroid, increased frequency of hospitalization and ultimately, renal failure. Long-term care, medication, frequent hospitalizations, and thoughts of future 
uncertainty will contribute to serious implications of health associated with quality of life [3]. A study by Selewski et al. (2015) reported that quality of life scores in old patients was lower compared to newer patients, mainly in social function and school activities [4].

The relapse incidence in nephrotic syndrome tend to increase over time, with the possibility of relapse after the first attack is approximately 30-40\% [5]. Long-term use of steroids could result in several side effects such as growth disturbances, hypertension, cataract, osteoporosis, moon face and obesity that raise concerns from parents and affect the parents' psychological factors [6]. A study by Manti et al. (2013) on the psychosocial and cognitive functions of patients with nephrotic syndrome, found that there was a positive association between severity of nephrotic syndrome with somatic and emotional/ behavioral disorder. Long-term use of steroids is also associated with anxiety and depression levels in children [7].

Assessment of quality of life is influenced by physical, mental, social and emotional states. Specific instruments to measure quality of life in patients with nephrotic syndrome are currently under development. A generic instrument, known as the Pediatric Quality of Life Inventory (PedsQL ${ }^{\mathrm{TM}}$ ), is commonly used instead. The instrument is chosen based on the age of patients, reliability, validity, and applicability. The reliability of this instrument is demonstrated through good internal consistency, with alpha coefficients range from 0.70 to 0.92 . Its validity is demonstrated in the field-level analysis as well as questions of the disease and management, thus representing not only chronic illnesses. The assessment is very simple and takes less than 5 minutes' time. The quality of life assessment in pediatric health services could facilitate physician-patient communication, improve patient/parental satisfaction, identify morbidity and assist clinical decision-making, e.g., whether refer patient or not to to psychiatrists or other professional care in accordance with its result [8].

Health-related quality of life (HRQOL) measurement is important as a complete bio-psycho-social health assessment $[3,9]$. The quality of life measurement is conducted to identify the patient's view on their lives and to determine their health status and how well they can function. Screening and interventions are needed for risky population in order to prevent disruptions in quality of life and provision of healthcare services [10].

A previous study by Gibson and colleagues (2013) found decreased quality of life in children with nephrotic syndrome particularly due to the presence of anxiety, fatigue, pain and limited mobility. The study, however, did not investigate the effect of duration of illness on the quality of life [11]. The effect of duration of illness on quality of life in children with nephrotic syndrome was studied by Selewski et al. (2015), who found that there was a significant disruption in quality of life among children with longer course of illness [12]. Another study by Rosita (2011) found no difference in quality of life in children with steroid-resistant nephrotic syndrome and relapsed nephrotic syndrome. In this study, there was no distinction between infrequent relapse with frequent relapse [13]. Approximately $65 \%$ of children with steroid-sensitive nephrotic syndrome had almost normal behavior at beginning of treatment but developed anxiety, depression and/or aggressive behavior during relapse. Children whose behavior was abnormal at the beginning of the study would got worsen during relapse period [14].

Early problem identification from frequent-relapse nephrotic syndrome and children with poor quality of life will lead to interventions for disrupted educational, physical, emotional or social function. Early identification and interventions on quality of life in children with infrequent and frequent relapse often decrease the prevalence of poor educational, occupational and social function outcomes in adulthood [14].

Hence, theres no study on quality of life in children with nephrotic syndrome, especially those with infrequent relapse and frequent relapse nephrotic syndrome in Indonesia. Thus, this study was conducted to determine the differences between quality of life in children with infrequent and frequent relapse of nephrotic syndrome.

\section{Materials and Methods}

This is an observational analytic study using cross-section method conducted at the Pediatric outpatient clinic in Sanglah Hospital, Denpasar, Indonesia. The study was conducted from January 2016 to January 2017. The inclusion criteria include: children with diagnosis of relapsed nephrotic syndrome aged 2 to 4 years old, and their parents whom willing to take part in the study (indicated by signing an informed consent form). Exclusion criteria were children with critical illness, severe intellectual disability, and major congenital abnormalities. This study was approved by the Research Ethics Committee of Udayana Medical School, Sanglah Hospital, Denpasar, Indonesia.

Quality of life is defined as the quality of life in children with nephrotic syndrome measured using PedsQL 4.0 Generic Core Scales questionnaire. The Parent report for toddlers (ages 2-4) of the PedsQL ${ }^{\mathrm{TM}} 4.0$ Generic Core Scales is composed of 21 items. The child (self) and parent reports for young children (ages 5-7), Children (ages 8-12) are composed of 23 items consist of 4 dimensions: a) Physical function (8 items), b) emotional function (5 items), c) social function ( 5 items), d) school function (3 items for toddlers and 5 items for older). School functioning in toddlers have to be completed only if the father / mother's son attends school or join child care. The questionnaire was scored using a 0-4 scale with $0=$ never; $1=$ almost never; $2=$ sometimes; $3=$ often; 4 = almost always). Each answer will be converted into a $0-100$ scale $(0=100 ; 1=75 ; 2=50 ; 3=25 ; 4=0)$.

Infrequently relapse of nephrotic syndrome refers to a condition which relapse occurs less than 2 times in the first 6 months after initial response or less than 4 times per year of observation. Frequent relapse nephrotic syndrome refers to a condition which relapse occurs $\geq 2$ times in the first 6 months after initial response or $\geq 4$ times within a period of 1 year.

The obtained data were analyzed by a computer program 
and presented in tabular forms. Categorical data was presented as percentages, while numerical data with normal distribution was presented as average and standard deviation (SD). The normality distribution of numerical data was determined by using Kolmogorov-Smirnov test. The mean differences in quality of life in infrequent-relapse and frequent-relapse nephrotic syndrome groups were tested using unpaired t-test if the distribution was normal, or with Mean-Whitney $U$ test if the distribution wasn't normal. A p-value of $\leq 0.05$ was considered significant with $95 \%$ confidence interval.

\section{Results}

Subjects were selected consecutively until a minimum number of 28 samples was achieved. The quality of life assessment was based on parental reports involving all subjects. Self-report was also asked from children aged $\geq 5$ years, (23 subjects). The basic characteristics of subjects are shown in Table 1.

Eighteen subjects $(64.28 \%)$ were male and 10 subjects (35.71\%) were female. Most subjects (12) were in 5-7 years old age group, while the 2-4 years and 8-12 years age groups consisted of 5 and 11 children, respectively. Half (50\%) of the subjects were in good nutritional status while the 2 children were undernourished, 5 were overweight, and 7 were obese.

In this study, most of the parents in the infrequent-relapse group graduated from senior high school while most of the parents in the frequent-relapse group graduated from junior high school education. In terms of monthly income, the number of parents with more than IDR 1,800,000/month income was equal to the number of parents who had less than IDR $1,800,000 /$ month. The mean duration of illness was 21.5 months in infrequent-relapse group, and 27.85 in frequent-relapse group.

The mean total of quality of life score based on the parents' reports was lower than the children's self-reports which was 85.70 in the infrequent-relapse group and 82.24 in the frequentrelapse group (Table 2). Based on the children's reports, the mean quality of life score was 88.79 in the infrequent-relapse group and 82.59 in the frequent-relapse group. This study found no significant differences in terms of physical, emotional, social, school functions subscales of the QoL score as well as the total quality of life score in both children's and parents' reports from infrequent-relapse and frequent-relapse groups $(p>0.05)$. The total quality of life score in the infrequent-relapse group was higher than that of the frequent-relapse group by 4.46 points in the parents' reports and by 6.2 points in the children's reports.

Table 1. Characteristics of subjects.

\begin{tabular}{lll}
\hline Characteristics & $\begin{array}{l}\text { Infrequent- } \\
\text { relapse NS (n=14) }\end{array}$ & $\begin{array}{l}\text { Frequent-relapse } \\
\text { NS (n=14) }\end{array}$ \\
\hline Age (years), n (\%) & & \\
$2-4$ & $4(80.0)$ & $1(20.0)$ \\
$5-7$ & $4(33.3)$ & $8(66.7)$ \\
$8-12$ & $6(54.5)$ & $5(45.5)$ \\
Gender, n (\%) & & \\
Male & $7(38.9)$ & $11(61.1)$ \\
Female & $7(70.0)$ & $3(30.0)$ \\
Nutritional status, n (\%) & & \\
Undernourished & $2(100.0)$ & $0(0.0)$ \\
Well-nourished & $7(50.0)$ & $9(75.0)$ \\
Overweight & $3(60.0)$ & $5(41.7)$ \\
Obese & $2(28.6)$ & $0(0.0)$ \\
Parents' education level & & $0(0.0)$ \\
Primary school & $2(100.0)$ & $9(75.0)$ \\
Junior high school & $3(25.0)$ & $5(41.7)$ \\
Senior high school & $7(58.3)$ & $0(0.0)$ \\
University & $2(100.0)$ & $9(64.3)$ \\
Parents' monthly income, n (\%) & & $5(35.7)$ \\
$<$ IDR 1.800.000 & $5(35.7)$ & $27.8(14.2)$ \\
$\geq$ IDR 1.800.000 & $9(64.3)$ & \\
Duration of disease (months), & $21.5(10.9)$ & \\
mean (SD) & & \\
\hline & &
\end{tabular}

In infrequent-relapse group, the highest subscale mean score was observed on physical function subscale (95.93) by children's reports while the lowest was observed in the school function subscale (70.91) by the parents' reports. In frequentrelapse group, the highest subscale mean value was found on emotional function (89.23) by children's reports and the lowest was for school function (63.07) by children's reports.

Table 2. The quality of life in children with relapse nephrotic syndrome.

\begin{tabular}{|c|c|c|c|c|c|c|c|c|}
\hline \multirow{2}{*}{ Parameter } & \multicolumn{3}{|c|}{ Infrequent-relapse NS } & \multicolumn{3}{|c|}{ Frequent-relapse NS } & \multirow{2}{*}{ Mean differences $(95 \%$ CI) } & \multirow{2}{*}{ P-value } \\
\hline & $\mathbf{n}$ & Mean & SD & n & Mean & SD & & \\
\hline Physical Function & & & & & & & & \\
\hline Parents' reports & 14 & 87.28 & 13.17 & 14 & 85.71 & 19.79 & $1.56(-11.49-14.62)$ & 0.808 \\
\hline $\begin{array}{l}\text { Children's reports }{ }^{\text {a }} \\
\text { Emotional Function }\end{array}$ & 10 & 95.93 & 5.90 & 13 & 87.26 & 18.55 & $8.67(-4.04-21.40)$ & 0.171 \\
\hline Parents' reports & 14 & 89.29 & 12.54 & 14 & 83.21 & 14.22 & $6.07(-4.34-16.48)$ & 0.242 \\
\hline $\begin{array}{l}\text { Children's reports }{ }^{\text {a }} \\
\text { Social Function }\end{array}$ & 10 & 89.00 & 9.94 & 13 & 89.23 & 9.54 & $-0.23(-8.72-8.26)$ & 0.956 \\
\hline Parents' reports & 14 & 92.86 & 11.39 & 14 & 88.21 & 12.95 & $4.64(-4.83-14.12)$ & 0.323 \\
\hline $\begin{array}{l}\text { Children's reports }{ }^{\text {a }} \\
\text { School Function }\end{array}$ & 10 & 94.00 & 10.75 & 13 & 88.08 & 14.07 & $5.92(-5.23-17.08)$ & 0.282 \\
\hline Parents' reports ${ }^{b}$ & 11 & 70.91 & 16.56 & 13 & 67.31 & 17.27 & $3.60(-10.80-18.00)$ & 0.609 \\
\hline $\begin{array}{l}\text { Children's reports }{ }^{\text {a }} \\
\text { Quality of life total score }\end{array}$ & 10 & 72.00 & 17.98 & 13 & 63.07 & 19.63 & $8.92(-7.64-25.49)$ & 0.275 \\
\hline Parents' reports & 14 & 85.70 & 8.96 & 14 & 82.24 & 12.56 & $3.45(-5.01-11.93)$ & 0.410 \\
\hline
\end{tabular}

a The children's reports was completed by children aged $\geq 8$ years old

${ }^{\mathrm{b}}$ The school function subscale of the questionnaire was completed by children aged $\geq 5$ years old. 


\section{Discussion}

The mean age of the subjects was 7.0 (3.59) years in the infrequent-relapse nephrotic syndrome group and 7.14 (2.21) years in the frequent-relapse group. The 5-7 years old age dominated this study (12 subjects). This is different with Rosita (2012) and Damanik (2006) who reported nephrotic syndrome patients were dominated by children age 8-15 years old. Age affects intellectual, social and emotional developments, thus further affect the children's perception of their quality of life $[12,15]$.

Patients with nephrotic syndrome receive glucocorticoid therapy to maintain remission. One of the potential side effects often found in glucocorticoid therapy is obesity. A study by Foster (2006) in United States on risk factors for obesity due to steroid usage found that the risk of obesity significant increased in steroid-sensitive nephrotic syndrome group who were exposed to steroid therapy within the last 6 months and after a steroid-free period of more than 6 months compared to normal control [16]. Obesity is associated with mental health that affects all aspects in ones quality of life. Physical health disorders that often caused by obesity, society's view of people with obesity and treatment factors, all will affect quality of life [17]. In this study, both groups demonstrated good nutritional status $(50 \%)$ but obesity was dominant in the frequent-relapse group.

Parents' level of education is an important factor in family's social status. It affects the compliance of medical treatment. In this study, most of the subjects' parents on infrequent-relapse group graduated from senior high school and most of the parents on frequent-relapse group graduated from junior high school. A study by Rosita et al. (2012) reported that most parents' in their study graduated from primary school [12].

Parents with lower income tend to ignore the needs of their children, which will affect their quality of life. In this study, we observed similar number of parents whose income less than IDR $1,800,000 /$ month and equal to or more than IDR $1,800,000 /$ month. Socioeconomic status, level of education, joblessness, income and possession of family health insurance affect children's quality of life. Families with higher socioeconomic status often pay more attention to their child health and have fund for their treatment. Socioeconomic status also affects health information obtained by parents, since most of the information was presented either through print or audio-visual media [18].

Duration of the disease also known can affect quality of life. The longer the duration of therapy, the worsen children's quality of life. However, quality of life will be good if education is properly given and if patients were compliant with the treatment. In this study, the duration of nephrotic syndrome was 21.5 (10.97) months in infrequent-relapse group and 27.85 (14.17) months in frequent-relapse group.

Nephrotic syndrome is a chronic disease which often treated with long-term corticosteroid. This disease often recurs and may lead to higher incidence of behavioral disorder compared to healthy children with the same age [1]. A study conducted by Guha et al (2010) on behavioral profiles of children with nephrotic syndrome found that nephrotic syndrome patients had higher incidence of behavioral disorder (68\%) than control group (21.6\%) [19]. This was in line with study conducted by Soliday et al, who found that children with nephrotic syndrome usually showed abnormal behavior while in recurrence state. This is likely due to the effect of prednisone doses administered during treatment [13].

Based on the bivariate analysis, the quality of life score in infrequent-relapse group did not differ statistically compared to frequent-relapse group; however, the mean survival score of infrequent-relapse group was slightly higher than that of frequent-relapse group. This might be due to longer or more frequent relapses, that the children and their family members' negative perception in quality of life decrease over time. This phenomenon is known as "response shift" and could also occur in other chronic diseases. The "response shift" is a result of changes by individual internal standard, personal values, perceptual concepts, thus affect behavior, cognitive and affective mechanisms of how ones address problem of his/her disease [20]. Overall, school functions had the lowest score and most responses were categorized as at risk, possibly due to frequent absence from schools due to hospitalization for control treatment (every 2 weeks to 1 month depending on laboratory results), inability to attend classes and even isolation from peer groups.

A study conducted in India by Agrawal et al. (2017) compared quality of life among children with nephrotic syndrome and other chronic diseases, the total value of quality of life in children with nephrotic syndrome was better than children with other chronic diseases. Further analysis showed that types of nephrotic syndrome (clinical phenotype) and demography did not affect the children's quality of life, whether in physical, emotional, social, or school functions [21].

Ruth et al. (2004), found that pediatric patients with nephrotic syndrome had lower social function scores than healthy children as measured using different questionnaires. The social function score was not related to the patients' age, sex, and socioeconomic level [22]. Different results were observed in this study, in which social function remains favorable in children with relapse nephrotic syndrome. Selewski, et al (2015), found significant lower scores in physical, emotional, social and school function among patients with nephrotic syndrome compared to normal populations by using PedsQL ${ }^{\mathrm{TM}}$ questionnaire. The duration of disease also affect children's quality of life. Nephrotic syndrome patients with longer duration of disease had lower quality of life compared to those with shorter duration of disease [4].

Measurement of quality of life have the advantages. It can be used as: an assessment of clinical intervention, screening test to identify children with specific difficulty whom would require counseling, early-recognition of additional non- 
medical interventions and to estimate health care costs [23].

\section{Conclusion}

There is no difference in the quality of life of children with infrequently-relapsing and frequently-relapsing nephrotic syndrome. The mean total quality of life score based on the parents' and children's reports in the infrequently-relapsing group was higher than in the frequently-relapsing group.

\section{Funding}

The authors received no financial support for the research, authorship, and/or publication of this article.

\section{References}

[1] Wirya IGNW. Sindrom Nefrotik. In: Buku Ajar Nefrologi Anak. $2^{\text {nd }}$ Ed. Jakarta: Balai Penerbit FKUI. 2002. p. 381-426.

[2] Nilawati GAP. 2012. Profil sindrom nefrotik pada ruang perawatan anak RSUP Sanglah Denpasar. 2012 [cited 2014 April 9]. Available from: http://saripediatri.idai.or.id/fulltext.asp?q=854.

[3] Eiser C. Children's quality of life measures. Arch Dis Child 1997; 77: 350-4.

[4] Selewski DT, Troost JP, Massegill SF, Gbadegesin RA, Greenbaum LA, Shatat IF. The impact of disease duration on quality of life in children with nephrotic syndrome: a Midwest Pediatric Nephrology Consortium study. Pediatr Nephrol 2015; 30: 1467-76.

[5] Vogt BA, Avner ED. Conditions particularly associated with proteinuria: nephrotic syndrome. In: Behrman, R. E., Kliegman, R. M., Jenson, H. B., editors. Nelson Textbook of Pediatrics. 17 ed. New Delhi: Elsevier India; 2004. p. 1753-7.

[6] Leonard MB, Feldman HI, Shulths J, Zemel BS, Foster BJ, Stalling YA. Long-term, high-dose glucocorticoids and bone mineral content in childhood glucocorticoid-sensitive nephrotic syndrome. N Engl J Med 2004; 352: 868-75.

[7] Manti P, Giannakopoulos G, Giouroukou E, Angelaki HG, Stefanidis CJ, Mitsioni A, et al. Psychosocial and cognitive function in children with nephrotic syndrome: association with disease and treatment variables. 2013 [cited 2014 July 20]. Available from: http://www.bpsmedicine.com/content/7/1/10.

[8] Varni JW. The PedsQL ${ }^{\mathrm{TM}}$ : measurement model for the pediatric quality of life inventory. Med Care 1999; 37: 126-39.

[9] Soetjiningsih. Tumbuh kembang anak dengan kondisi kesehatan kronik. In: Narendra MB, Sularyo T, Soetjiningsih, Suyitno H, Ranuh IGN, Wiradisuria S, editors. Buku Ajar II Tumbuh Kembang Anak dan Remaja. Jakarta: Sagung Seto; 2005. p. 61-9.
[10] Ravens-Sieberer U, Gosch A, Abel T, Auquier P, Bellach B, Bruil J, et al. Quality of life in children and adolescents: European public health perspective. European KIDSCREEN Group 2001; 46: 294-302.

[11] Gipson DS, Messer KL, Tran CL, Herreshoff EG, Samuel JP, Massengill SF, et al. Inpatient health care utilization in the United States among children, adolescents, and young adults with nephrotic syndrome. Am J Kidney Dis 2013; 61: 910-7.

[12] Rosita IR. Perbedaan kualitas hidup anak dengan sindrom nefrotik resisten steroid dan sindrom nefrotik relaps. 2013 [cited 2014 July 22]. Available from: http://eprints.undip.ac.id/33308/1/Ika Rara.pdf.

[13] Soliday E, Grey S, Lande MB. Behavioral effects of corticosteroids in steroid-sensitive nephrotic syndrome. Pediatrics 1999; 104: 51.

[14] Niaudet P. Long-term outcome of children with steroidsensitive idiopathic nephrotic syndrome. Clin J Am Soc Nephrol 2009; 4: 1547-8.

[15] Damanik MP. Hubungan antara human leucocyte antigens (HLA) dengan NS primer pada anak di RSUP Dr. Sardjito Yogyakarta. (Disertasi). Yogyakarta: Medica Fakultas Kedokteran Universitas Gajah Mada Yogyakarta; 2006.

[16] Foster BJ, Shults J, Zemel BS, Leonard MB. Risk factors for glucocorticoid-induced obesity in children with steroidsensitive nephrotic syndrome. Pediatr Nephrol 2006; 21: 97380 .

[17] Taylor VH, Forhan M, Vigod SN, Mclntyre RS, Morrison KM. The impact of obesity on quality of life. Best Pract Res Clin Endocrinol Metab 2013; 27: 139-46.

[18] Apter AJ, Reisine ST, Wallack Z, Affleck G, Barows E. The influence of demographic and socioeconomic factors on health-related quality of life in asthma. J Allergy Clin Immunol Pract 1999; 103: 72-8.

[19] Guha P, De A, Ghosal M. Behavior profile of children with nephrotic syndrome. Indian J Psychiatry 2010; 2: 122-6.

[20] Sprangers MA, Schwartz CE. Integrating response shift into health-related quality of life research: a theoretical model. Soc Sci Med 1999; 48: 1507-15.

[21] Agrawal S, Krishnamurthy S, Naik BN. Assessment of quality of life in children with nephrotic syndrome at a Teaching Hospital in South India. Saudi J Kidney Dis Transpl 2017; 28: 593-8.

[22] Ruth EM, Landolt MA, Neuhaus TJ, Kemper MJ. Healthrelated quality of life and psychosocial adjustment in steroidsensitive nephrotic syndrome. J Pediatr 2004; 14: 778-83.

[23] Varni JW. The PedsQL ${ }^{\mathrm{TM}}$ : measurement model for the pediatric quality of life inventory. Med Care 1999; 37: 126-39. 